Article

\title{
Pulsed Electric Field Extraction and Antioxidant Activity Determination of Moringa oleifera Dry Leaves: A Comparative Study with Other Extraction Techniques
}

\author{
Eleni Bozinou ${ }^{1}$, Ioanna Karageorgou ${ }^{1}$, Georgia Batra ${ }^{1}$, Vassilis G. Dourtoglou ${ }^{2} \oplus$ and \\ Stavros I. Lalas ${ }^{1, *}$ \\ 1 Department of Food Technology, Technological Educational Institute of Thessaly, Terma N. Temponera str., \\ GR-43100 Karditsa, Greece; empozinou@gmail.com (E.B.); ikarageorg@hotmail.com (I.K.); \\ gogo.batra@gmail.com (G.B.) \\ 2 Department of Wine, Vine and Beverage Sciences, University of West Attica, Agiou Spyridonos str., \\ GR-12210 Athens, Greece; vdourt@uniwa.gr \\ * Correspondence: slalas@teilar.gr; Tel.: +30-24410-64783
}

Received: 7 December 2018; Accepted: 9 January 2019; Published: 13 January 2019

\begin{abstract}
The scope of this work was to determine the possibility of the application of the pulsed electric field (PEF) technique to the production of extracts from Moringa oleifera plant material (freeze-dried leaves). Various PEF conditions (pulse duration-PD; and pulse interval-PI) were tested. A field strength of $7 \mathrm{kV} / \mathrm{cm}$ was used. The total phenols in the extracts were evaluated by the Folin-Ciocalteu method and the antioxidant activity was evaluated by the radical scavenging activity $\left(\mathrm{DPPH}^{\bullet}\right)$, ferric reducing antioxidant power (FRAP) and Rancimat methods. The results were compared with those of the extracts obtained using other extraction techniques, namely microwave-assisted and ultrasound-assisted extractions, simple boiling water extraction, and plain maceration with water (as the control). The highest extraction of total phenols was achieved by the PEF procedure using $40 \mathrm{~min}$ treatment at a PD of $20 \mathrm{msec}$ and a PI of $100 \mu \mathrm{sec}$. Additionally, all methods for the determination of the antioxidant activity showed that the activity of the extracts was proportional to the total phenol content. Concerning the PEF procedure, a low pulse duration with a high pulse interval is proposed in order to achieve higher extraction efficiency.
\end{abstract}

Keywords: pulsed electric field; Moringa oleifera; freeze-dried leaves; extraction; antioxidant activity

\section{Introduction}

The major challenges of conventional extraction methods are long extraction times, the requirement of costly and high purity solvents, evaporation of the huge amount of solvent, low extraction selectivity and the thermal decomposition of thermo labile compounds [1]. New and promising extraction techniques have been introduced so as to overcome these limitations. One of these non-conventional novel techniques is extraction with the use of a pulsed electric field (PEF) [2]. The main interest of this non-thermal technology is cell disruption, which leads to increased membrane permeability and the improved mass transfer of inner liquid and cell components from the intracellular vacuoles [3,4]. Moreover, it leads to an improved extraction yield, decreased processing time, facilitation of the purified extract, the decreased intensity of the conventional extraction parameters, the reduction of heat-sensitive compounds' degradation, and the reduction of energy costs and environmental impact [5]. 
The ability of PEF to cause electroporation to the cell membranes increases the diffusion efficiency of the valuable plant compounds of plant tissues at ambient temperatures. This "cold" extraction assisted by PEF impedes the degradation of the cell wall, as well as, the extraction of components like pectins, oligo- and polymolecular compounds into the fluid [6]. Since, extraction at high temperatures results in the acceleration of diverse chemical reactions between the extracted components (i.e., the color appearance because of the Maillard reaction) [6], PEF technology appears suitable as a method for the extraction of pure dry matter, carotenoids, vitamins, sucrose, proteins, inulin and other substances [7].

El-Belghiti and Vorobiev [8] found that the application of PEF to sugar beet slices and the subsequent diffusion $(2 \mathrm{~h}$ ) at ambient temperature led to a recovery of about $93 \%$ in solute yield compared to the $40 \%$ obtained in untreated samples. Other authors [9] observed that the juice purity was higher for slices pretreated by PEF than for the untreated slices after thermal diffusion at $70{ }^{\circ} \mathrm{C}$. PEF was also previously used for the extraction of inulin from chicory tissues [10], anthocyanins from red cabbage [11], podophyllotoxin from Podophyllum peltatum [12], polyphenols from fresh tea leaves [13], chitosan from shrimp shells [14], calcium from fishbone [15], and crocin, safranal and picrocrocin from Crocus sativus [16]. In another study [17], the impact of PEF treatment on the yield and quality parameters $(\mathrm{pH}$, soluble solids, total dry matter, color, total carotenoids as $\beta$-carotene and vitamin $\mathrm{C}$ ) of juice obtained from paprika was investigated. PEF has also been applied for the extraction of aroma compounds from toasted wood in order to flavor wines [18].

Another non-conventional extraction technique uses ultrasound. The use of ultrasound is a novel, clean, green extraction technology for various molecules and biomaterials, including polysaccharides, essential oils, proteins, peptides, fine chemicals (dyes and pigments) and bioactive molecules of commercial importance [19]. Ultrasound is based on a phenomenon called cavitation. Practically, this means the production, growth and collapse of bubbles [2]. The extraction mechanism during ultrasound involves two types of physical phenomena: diffusion across the cell wall and the rinsing of the cell contents after the walls have broken [20]. Among the advantages of using ultrasound are the reductions in extraction time, energy and use of solvent. The ultrasound energy used for extraction facilitates more effective mixing, selective extraction, faster energy transfer, a faster response to process extraction control, reduced thermal gradients and extraction temperature, quick start-up, reduced equipment size, increased production and elimination of the process steps [2,21]. Ultrasound is an effective extraction technique for bioactive compounds from herbal plants, such as daidzin, genistin, glycitin and malonyl genistin from soybean [22], rutin, naringin, naringenin, quercetin, ellagic acid and kaempferol from strawberries [23], chlorogenic acid from the fresh leaves, fresh bark and dried bark of Eucommia ulmodies Oliv. [24], rutin and quercetin from Euonymus alatus (Thund.) Sieb [25], vindoline, catharanthine and vinblastine from Catharanthus roseus [26], anthocyanins and phenolic compounds from grape peel [27], phenolcarboxylic acids, carnosic acid and rosmarinic acid from Rosmarinus officinalis [28] and many others.

Another method used for the extraction of soluble compounds into a liquid medium is microwave energy [29]. Microwaves (MW) are electromagnetic waves ( 0.1 to $3 \mathrm{GHz}$ ) and are a combination of electric and magnetic fields, spreading electromagnetic energy, which acts as non-ionizing radiation causing the molecular motion of ions and the rotation of the dipoles, resulting in the release of thermal energy [30]. The factors that may influence the performance of MW include the nature of the solvent, the solvent to feed ratio, extraction time, microwave power, temperature, sample characteristics, the effect of stirring and optimum operating conditions [31]. MW were already used for the extraction of polyphenols and caffeine from green tea leaves [32], ginsenoside from ginseng root [33], flavolignin, silybinin from Silybum marianum [34], E- and Z-guggolsterone, cinnamaldehyde and tannin from various plants [35], bound phenolic acids from bran and flour fractions of sorghum and maize of different hardness [36], flavonoids and phenolics from Chaenomeles sinensis [37] and many others.

Moringa oleifera is a dicotyledonous tropical and sub-tropical flowering tree species, native to the sub-Himalayan tracts, widely known as a multi-purpose tree (also known as "miracle tree"). M. oleifera's leaves have a high content of total phenols (myricetin, quercetin, kampherol) 
with high antioxidant, antimutagenic and anticarcinogenic properties [38], while different parts of the plant (roots, leaves, flowers, fruits and seeds) contain phytochemicals such as alkaloids, flavonoids, carotenoids, tannins, anthraquinones, anthocyanins and proanthocyanidins [39]. Specific parts of M. oleifera also exert many pharmacological activities such as anticancer, antioxidant, anti-inflammatory, immunomodulatory, antidiabetic, antifungal, antibacterial, hepatoprotective [39], antidyslipidemic, anthelmintic, antihyperglycemic, antimicrobial, antiproliferative, antiulcer and antiurolithiatic activity [40].

In this study, freeze-dried M. oleifera leaves were subjected to extraction with PEF. The total phenol content and the antioxidant activity of the extracts were determined. The efficiency of the PEF extraction was compared with other well known methods, namely microwave-assisted and ultrasound-assisted extraction, simple boiling water extraction, and plain maceration (as the control). To the best of our knowledge, there are no other studies concerning the extraction of M. oleifera leaves using PEF technology.

\section{Materials and Methods}

\subsection{Plant Material}

M. oleifera seedlings were cultivated in the Agioi Apostoloi area (at $39^{\circ} 22^{\prime} 39.4^{\prime \prime} \mathrm{N}$ and $21^{\circ} 54^{\prime} 00.6^{\prime \prime} \mathrm{E}$ and elevation of $100 \mathrm{~m}$, according to Google Earth Pro version 7.3.2.5491 (64bit) (Google, Inc., Mountain View, CA, USA) of Karditsa County (central Greece). The leaves from the plants were collected during the morning of 25 October 2018, when the trees were 2 months old. They were delivered to the Food Analysis Lab at the Department of Food Technology of T.E.I. of Thessaly (Karditsa, Greece) $30 \mathrm{~min}$ after collection. Afterwards, they were thoroughly washed with tap water and freeze dried using a Telstar Cryodos 80 freeze dryer (Telstar Industrial, S.A., Terrassa, Spain) for $12 \mathrm{~h}$ (the moisture content of the leaves was $8 \%$ ) and milled to particle sizes of about $0.5 \mathrm{~mm}$ using a blender. Finally, they were stored in vacuum-sealed polyethylene bags in the dark at ambient temperature $\left(25^{\circ} \mathrm{C}\right)$ until they were used for experiments, i.e., within 3 days.

In all extraction methods, the amount of the dried leaves used was $5 \%(w / v)$ and, specifically, $1.25 \mathrm{~g}$ of freeze-dried leaves was mixed with $25 \mathrm{~mL}$ of double distilled (DD) water. Immediately after each extraction treatment, the mixture of water and plant material was filtered through filter paper. In order to have the same final volume of water, the residue in the filter was rinsed with DD water, until a final volume of $25 \mathrm{~mL}$ of the filtered sample was reached.

\subsection{PEF Apparatus}

The PEF equipment used was a static bench scale system. The PEF equipment layout consisted of a high voltage power generator (Leybold, LD Didactic GmbH, Huerth, Germany), a digital oscilloscope (Rigol DS1052E, Rigol Technologies, Inc, Beaverton, OR, USA), a pulse generator (UPG 100, ELV Elektronik AG, Leer, Germany) and a treatment chamber (Val-Electronic, Athens, Greece).

The PEF generator could provide a maximum voltage of $25 \mathrm{kV}$. This generator provided monopolar, rectangular-shaped pulses. The signals of the voltage, the current, frequency, and pulse waveform were monitored by the digital oscilloscope.

The treatment chamber was made of stainless steel with Teflon screw caps in both ends. The positive electrode was attached on a stainless steel cylinder (150 $\mathrm{mm}$ in length, $26 \mathrm{~mm}$ internal diameter). The negative electrode was attached on a stainless steel cylinder (6 $\mathrm{mm}$ in diameter and $140 \mathrm{~mm}$ in height) which was placed inside the first cylinder. The sample (freeze-dried leaves + DD water) was poured in the treatment chamber and the steel negative electrode was screwed in. The electric field strength, $E$, was calculated as $E=U / d$, where $U$ is the applied voltage and $d$ is the distance between the electrode and the stainless steel cylinder $(d=1 \mathrm{~cm})$. The electric field strength $(E)$ was set at $7 \mathrm{kV} / \mathrm{cm}$. 
The variables included the pulse duration (PD), which is the period of time during which the electric field is applied; and the pulse interval (PI), which is the period between two pulse applications.

\subsection{Extraction Procedures}

\subsubsection{PEF Extraction}

Once the freeze-dried M. oleifera leaves and the DD water were introduced into the treatment chamber, the PEF application started. The pulses were monitored by the oscilloscope during the whole treatment. The experiment was divided into two parts. For the first part, the PD was kept constant while the PI was altered. In the second part, the PI was kept constant while the PD was changing. The treatment time was the same $(40 \mathrm{~min})$ in all experiments. The details of the above conditions are presented in Table 1.

Table 1. Sample names and extraction conditions.

\begin{tabular}{ccccc}
\hline \multirow{2}{*}{ Sample Name } & \multicolumn{4}{c}{ Extraction Conditions } \\
\cline { 2 - 5 } & $\begin{array}{c}\text { Time } \\
(\mathbf{m i n})\end{array}$ & $\begin{array}{c}\text { Temperature } \\
\left({ }^{\circ} \mathbf{C}\right)\end{array}$ & $\begin{array}{c}\text { Pulse Duration (PD) } \\
(\mathbf{m s e c})\end{array}$ & $\begin{array}{c}\text { Pulse Interval (PI) } \\
(\boldsymbol{\mu s e c})\end{array}$ \\
\hline PEF 1 & 40 & Ambient & 10 & 100 \\
PEF 2 & 40 & Ambient & 10 & 75 \\
PEF 3 & 40 & Ambient & 10 & 50 \\
PEF 4 & 40 & Ambient & 10 & 25 \\
PEF 5 & 40 & Ambient & 20 & 100 \\
PEF 6 & 40 & Ambient & 50 & 100 \\
PEF 7 & 40 & Ambient & 70 & 100 \\
PEF 8 & 40 & Ambient & 100 & - \\
Microwave (350 W) & 2 & 80 & - & - \\
Ultrasound & 15 & 36 & - & - \\
Boiling water & 2 & $100-88$ & - & - \\
Control & 40 & Ambient & - & - \\
\hline
\end{tabular}

The temperature of the contents of the treatment chamber was checked after treatment with an infrared thermometer (GM300, Benetech, Shenzhen Jumaoyuan Science and Technology Co., Ltd., Shenzhen, China). It was observed that there was no significant increase in the temperature $\left(\Delta t<1^{\circ} \mathrm{C}\right)$. After treatment, the mixture was filtered through filter paper. The residue was rinsed with about $9.7 \mathrm{~mL}$ of $\mathrm{DD}$ water in order to replenish the water absorbed by the plant material during the procedure.

\subsubsection{Extraction with Boiling Water}

After the DD water reached boiling point $\left(\sim 100{ }^{\circ} \mathrm{C}\right)$, the freeze-dried leaves were added to the beaker and then the mixture was left for $2 \mathrm{~min}$ (without heating). The temperature at the end of the extraction time was $88^{\circ} \mathrm{C}$ (Table 1). After treatment, the mixture was filtered through filter paper. The residue was rinsed with about $15.4 \mathrm{~mL}$ of DD water in order to replenish the water evaporated or absorbed by the plant material during the procedure.

\subsubsection{Microwave Extraction}

After the freeze-dried leaves were immersed in DD water, the mixture was exposed to microwaves in a microwave oven (Candy CMW 1770 M, Candy Hoover S.r.I., Brugherio, Italy) (maximum power $700 \mathrm{~W}$ ), operating at $350 \mathrm{~W}$ for $2 \mathrm{~min}$. The sample temperature after the microwave treatment was approximately $80{ }^{\circ} \mathrm{C}$ (Table 1 ). After treatment, the mixture was filtered through filter paper. The residue was rinsed with about $13.5 \mathrm{~mL}$ of DD water in order to replenish the water evaporated or absorbed by the plant material during the procedure. 


\subsubsection{Ultrasound Extraction}

Ultrasound treatment was determined using an Elmasonic S $100 \mathrm{H}$ ultrasound bath (Elma GmbH and Co. K.G., Singen, Germany). The freeze-dried leaves were immersed in DD water in a beaker, which was then placed inside the bath and exposed to the ultrasound treatment. The ultrasound bath operated at a power of $150 \mathrm{~W}$ and a frequency of $37 \mathrm{kHz}$, while the treatment duration was $15 \mathrm{~min}$. The temperature of the bath was set to ambient and the temperature during the treatment never exceeded $36{ }^{\circ} \mathrm{C}$ (Table 1). Immediately after treatment, the mixture was filtered through filter paper. The residue was rinsed with about $10.5 \mathrm{~mL}$ of DD water in order to replenish the water evaporated or absorbed by the plant material during the procedure.

\subsubsection{Control Sample}

A control sample was prepared for comparison purposes. This sample was prepared using the same quantity of both freeze-dried leaves and DD water. The leaves remained in water for $40 \mathrm{~min}$ (at ambient temperature), which was equal to the duration of the PEF procedure (Table 1), and then the mixture was filtered through filter paper. The residue was rinsed with about $9.6 \mathrm{~mL}$ of DD water in order to replenish the water evaporated or absorbed by the plant material during the procedure.

\subsection{Determination of the Total Phenol Content}

A previously described protocol [41] was used for the determination of the total phenols. Briefly, $0.78 \mathrm{~mL}$ of distilled water, $0.02 \mathrm{~mL}$ of the sample extract and $0.05 \mathrm{~mL}$ of Folin-Ciocalteu reagent (2 M) (Merck, Darmstadt, Germany) were added in a $1.5 \mathrm{~mL}$ Eppendorf tube. After exactly $3 \mathrm{~min}$, $0.15 \mathrm{~mL}$ of anhydrous sodium carbonate $\left(\mathrm{Na}_{2} \mathrm{CO}_{3}\right)$ (Merck) $20 \%(w / v)$ was added to the tube and the mixture was allowed to stand at room temperature in the dark for $60 \mathrm{~min}$. The absorbance was read at $750 \mathrm{~nm}$ in a Shimadzu UV-1700 UV/Vis spectrophotometer model (Shimadzu, Tokyo, Japan), and the total phenol concentration $\left(\mathrm{C}_{\mathrm{TP}}\right)$, expressed in $\mathrm{mg} / \mathrm{g}$ of dry matter (d.m.), was calculated from a calibration curve (25-200 mg/g), using gallic acid (Sigma-Aldrich, Hohenbrunn, Germany) as a standard. Total phenols content (TPC) was determined as mg of gallic acid equivalents (GAE) per $g$ of the freeze-dried $M$. oleifera leaves, using the following equation:

$$
\operatorname{TPC}(\mathrm{mg} \text { GAE} / \mathrm{g} \text { of d.m. })=\frac{C_{\mathrm{TP}} \times V}{w}
$$

where $V$ is the volume of the extraction medium (in $\mathrm{L}$ ); and $w$ is the weight of the Moringa oleifera sample (in $g$ of d.m.).

\subsection{Determination of Antioxidant Activity}

\subsection{1. $\mathrm{DPPH}^{\bullet}$ Assay}

For the determination of antioxidant activity $\mathrm{DPPH}^{\bullet}$ (2,2-diphenyl-1-picrylhydrazyl) (Sigma-Aldrich) assay was used. The assay was performed using a well established methodology [42]. A volume of $0.025 \mathrm{~mL}$ sample extract was mixed with $0.975 \mathrm{~mL} \mathrm{DPPH}^{\bullet}$ solution $(80 \mu \mathrm{M}$ in methanol) and the absorbance at $515 \mathrm{~nm}$ (using a Shimadzu UV-1700) was read immediately after mixing $\left(A_{515(i)}\right)$ and after exactly $30 \mathrm{~min}\left(A_{515(f)}\right)$. The capacity to scavenge the $\mathrm{DPPH}^{\bullet}$ radical was expressed as:

$$
\text { Inhibition }(\%)=\left(\frac{A_{515(i)}-A_{515(f)}}{A_{515(i)}}\right) \times 100
$$

\subsubsection{Ferric Reducing Ability (FRAP Assay)}

The determination of antioxidant activity was also determined by the use of a FRAP assay. Determinations were performed according to a previously described protocol [43]. Sample extract 
$(0.05 \mathrm{~mL})$ was mixed thoroughly with $0.05 \mathrm{~mL} \mathrm{FeCl}_{3}$ (Merck) solution $(4 \mathrm{mM}$ in $0.05 \mathrm{M} \mathrm{HCl})$, and incubated for $30 \mathrm{~min}$ in a water bath at $37^{\circ} \mathrm{C}$. Next, $0.90 \mathrm{~mL}$ TPTZ (Sigma-Aldrich) solution $(1 \mathrm{mM}$ in $0.05 \mathrm{M} \mathrm{HCl}$ ) was added, and the absorbance was recorded at $620 \mathrm{~nm}$ (using a Shimadzu UV-1700) after exactly $5 \mathrm{~min}$. Ascorbic acid (Sigma-Aldrich) concentration $\left(\mathrm{C}_{\mathrm{AA}}\right)$, expressed in $\mu \mathrm{moL} / \mathrm{g}$, was calculated from a calibration curve $(20-100 \mu \mathrm{moL} / \mathrm{g})$. The reducing power $\left(\mathrm{P}_{\mathrm{R}}\right)$ was determined as $\mu \mathrm{moL}$ ascorbic acid equivalents ( $\mu \mathrm{moL} \mathrm{AAE}$ ) per $\mathrm{g}$ of the freeze-dried M. oleifera leaves, using the following equation:

$$
\mathrm{P}_{\mathrm{R}}(\mu \mathrm{moL} \text { AAE} / \mathrm{g} \text { of d.m. })=\frac{C_{\mathrm{AA}} \times V}{w}
$$

where $V$ : is the volume of the extraction medium (in L); $w$ : the weight of Moringa oleifera sample (in $g$ of d.m.).

\subsubsection{Rancimat Method}

The antioxidant activity of the extracts was determined by the Rancimat method as described by Lalas et al. [38]. Specifically, each extract was accurately weighed to obtain $5000 \mathrm{ppm}$ in purified (according to the method of Fuster et al. [42]) sunflower oil and its activity was determined using a Metrohm Rancimat 743 (Metrohm Ltd., Herisau, Switzerland), along with another sample of sunflower oil without the addition of the extract, as the control. The conditions were set to $90^{\circ} \mathrm{C}$ and $15 \mathrm{lt} / \mathrm{min}$. The protection factor $(\mathrm{PF})$ was calculated as shown below:

$$
\mathrm{PF}=\frac{\text { induction period with antioxidant }}{\text { induction period without antioxidant }}
$$

A PF greater than 1 indicates the inhibition of lipid oxidation. The higher the value of PF, the better the antioxidant activity observed [44].

\subsection{Statistical Analysis}

The results are displayed as the means of three determinations. The standard deviation (SD) is given in parentheses. The statistical significance (at $p<0.05$ ) of the differences between the mean values was assessed by the ANOVA test using SPSS software (SPSS Inc., Chicago, IL, USA).

\section{Results and Discussion}

Brodelius et al. [45] were the first to carry out a study concerning improvement of the extraction of intracellular compounds with high added value by the application of pulsed electric fields [46]. They were interested in extracting berberine and betacyanins from Chenopodium rubrum and C. rubrum. They succeeded in extracting these compounds from plant cells; however, this was only after the irreversible electroporation of the cells. Dörnenburg and Knorr [47], confirmed this conclusion after intracellular pigment (amarantine and antrachinone) extraction trials from two plants, C. rubrum and Morinda Citrifolia. Fincan et al. [48] also revealed that the extraction of betanin, a red beet pigment, was possible after the irreversible electroporation of cells. Tedjo et al. [49] and Boussetta et al. [50] made a successful effort to extract polyphenols from the skin and seeds of grape, respectively. According to Eshtiaghi and Knorr [51], the sugar contained in the cells of sugar beets can also be extracted effectively after irreversible electroporation of the membranes. Coconut milk has also been extracted with this technology [52]. In another study, the PEF treatment of Chlorella vulgaris algae with a $15 \mathrm{kV} / \mathrm{cm}$ field strength increased protein, chlorophyll and carotenoid concentrations of the extracts [53].

Delsart [46] also reported that the use of a pulsed electric field as pretreatment or in combination with extraction by the pressing of fruit and vegetable juices (apple juice, carrots, spinach, sugar beets, beans, artichokes, red cabbages, potatoes, onions, and grapes) was found to be very promising since the extraction efficiency was significantly improved. Similarly, the extraction of vegetable oil (corn oil, olive oil and soybean oil) was greatly improved. 
During the present work, the effect of PEF on the production of extracts from the freeze-dried M. oleifera leaves was studied for the first time (to our knowledge). Various PEF conditions (different PD and PI) were tested in order to optimize the procedure. Monitoring of the extraction in order to achieve optimization was carried out by means of the total phenol concentration (using the Folin-Ciocalteu method). At the same time, the PEF results were compared to those of other known extraction techniques. The antioxidant activity of the extracts from each one of the tested conditions/techniques was also determined using various methods ( $\mathrm{DPPH}^{\bullet}$, FRAP, Rancimat method).

\subsection{Total Phenol Content of the Extracts}

Initially, the mixture of the freeze-dried leaves and water was submitted to various PEF conditions and other extraction methods. The results are presented in Table 2.

Table 2. Total polyphenol content of the extracts.

\begin{tabular}{cc}
\hline Sample Name & Total Polyphenol Content (mg GAE/g of Dry Matter) \\
\hline PEF 1 & $24.72(0.22)^{\mathrm{a} *}$ \\
PEF 2 & $27.04(0.39)^{\mathrm{b}}$ \\
PEF 3 & $33.12(0.38)^{\mathrm{c}}$ \\
PEF 4 & $38.24(0.42)^{\mathrm{d}}$ \\
PEF 5 & $40.24(0.81)^{\mathrm{e}}$ \\
PEF 6 & $34.96(0.95)^{\mathrm{f}}$ \\
PEF 7 & $32.90(0.48)^{\mathrm{c}}$ \\
PEF 8 & $31.60(0.56)^{\mathrm{g}}$ \\
Microwave (350 W) & $36.59(0.33)^{\mathrm{h}}$ \\
Ultrasound & $29.04(0.21)^{\mathrm{i}}$ \\
Boiling water & $31.56(0.71)^{\mathrm{g}}$ \\
Control & $27.76(0.34)^{\mathrm{b}}$ \\
\hline
\end{tabular}

* The results are presented as the means of three determinations. The standard deviation (SD) is given in parentheses. The different superscript letters denote statistically significant difference $(p<0.05)$.

It appears that the highest extraction of polyphenols was achieved by the PEF 5 procedure, applying PD and PI of $20 \mathrm{msec}$ and $100 \mu \mathrm{sec}$, respectively. The lowest extraction of total polyphenols was achieved by PEF 1, PEF 2 and the control (maceration-freeze-dried leaves in water for $40 \mathrm{~min}$ ).

Apart from PEF 3 and 7, there were significant differences $(p<0.05)$ between the various PEF conditions. It appears that decreasing the PI (from 100 to $25 \mu \mathrm{sec}$ ) while retaining the PD at $10 \mathrm{msec}$ increases the extraction efficiency of the PEF procedure. Increasing the PD (from 20 to $100 \mathrm{msec}$ ) while retaining the PI at $100 \mu \mathrm{sec}$ reduces the quantity of extracted total polyphenols (Table 2). Therefore, a low PD with a high PI is proposed as the best condition for the extraction of total polyphenols from the freeze-dried M. oleifera leaves.

Apart from the PEF 5 and PEF 4 procedures, a high extraction of total phenols was achieved by microwave-assisted extraction. In comparison to PEF, the microwave-assisted procedure extracted fewer (significant at $p<0.05)$ polyphenols than PEF 4 and 5 but significantly more $(p<0.05)$ than all the other PEF conditions/procedures (Table 2).

The heating (boiling) procedure extracted significantly more $(p<0.05)$ phenols than PEF 1 , PEF 2 , the ultrasound-assisted extraction procedure and the control but fewer (significant at $p<0.05$ ) from all other conditions / procedures of PEF (except for PEF 8, which showed no significant difference).

Similarly, the ultrasound procedure extracted significantly more $(p<0.05)$ phenols than PEF 1 , PEF 2 and the control but fewer (significant at $p<0.05$ ) compared to all the other conditions/procedures of PEF.

As indicated by the results (Table 2), the PEF procedure could be a viable alternative for the extraction of phenols from the freeze-dried M. oleifera leaves. Microwave-assisted extraction is a very fast method that can significantly increase the concentration of phenols in the extraction medium. However, in large industrial or semi-industrial scales, it requires expensive equipment 
and demands high-energy consumption. Furthermore, this procedure significantly increases the temperature of the sample and the extraction medium-something that can, in many cases, cause the partial destruction or loss of some of the important compounds (i.e., essential oils, etc.) of the extracted material. Extraction with heating (boiling) is the oldest and most commonly used technique. It is fast and uses relatively low-cost equipment that is also easy to operate. However, it has high energy consumption and, of course, a high temperature is used, which can, in many cases (like microwave-assisted extraction), cause the partial destruction or loss of some of the important compounds of the extracted material. Ultrasound-assisted extraction is also a fast method that can increase the concentration of valuable compounds in the extraction medium. However, again, in large industrial or semi-industrial scale applications, it requires expensive equipment and has high energy consumption. It does not significantly increase the temperature of the sample (or the extraction medium) but its ability for extraction appears lower compared to microwave extraction and the heating (boiling) procedure. PEF, alternatively, is less power demanding (and hence more cost effective) and more importantly, it does not increase the temperature (usually $<1^{\circ} \mathrm{C}$ ), which means that the extraction of high-value components is possible, especially in the case of sensitive compounds or materials. However, as a relatively new technique, it may require special equipment/machinery, which could be expensive at present.

\subsection{Antioxidant Activity of the Extracts}

The antioxidant activity of the extracts was determined by using three different methods, namely, the $\mathrm{DPPH}^{\bullet}$ (radical scavenging activity), FRAP (ferric reducing antioxidant power) and Rancimat methods. These different methods were selected in order to determine the potential of the extracts in providing antioxidant protection under different conditions. Specifically, the DPPH${ }^{\bullet}$ method measures the ability of an extract (or compound) to reduce (the \% of disappearance/reduction is determined) a stable free radical (i.e., $\mathrm{DPPH}^{\bullet} ; \mathrm{C}_{18} \mathrm{H}_{12} \mathrm{~N}_{5} \mathrm{O}_{6}, \mathrm{M}=394.33$ ). This method mainly determines the ability of a compound to donate a hydrogen atom [54], which is one of the abilities of "primary" antioxidants. The FRAP method relies on the reduction of the complex ferric ion-TPTZ [55], meaning that it is measuring the ferric-reducing ability of a compound. This method determines mainly the ability of a compound to chelate ferric ions (catalysts of oxidation reactions), which is another ability (different than the one determined by the $\mathrm{DPPH}^{\bullet}$ method) of a "primary" antioxidant. Finally, with the Rancimat method, the resistance of fats and oils to oxidation is measured. The method is generally used for lipids. However, it can also be used for the screening of antioxidant activity provided by a compound or extract on a real food (vegetable oil). The method is based on the measurement of the induction time, which decreases with the degradation of a lipid. The induction time depends on the type of lipid, the degree of unsaturation and the added antioxidants. One of the advantages of the Rancimat method is that it determines change in a "real" food (which is not the case with the two previously described methods). However, the method uses accelerated conditions (elevated temperature and high air current) which can cause some compounds or extracts to give false negative results (i.e., $\alpha$-tocopherol).

The results of the \% reduction of the $\mathrm{DPPH}^{\bullet}$ radical $\left(\mathrm{DPPH}^{\bullet}\right.$ method) are shown in Table 3. It appears that the \% reduction is proportional to the total phenols content of the extracts. The highest reduction was achieved by the PEF 5 procedure, which caused almost total $(98.31 \%)$ disappearance of the $\mathrm{DPPH}^{\bullet}$ radical. The lowest reduction was achieved by the control sample (maceration-freeze-dried leaves in water for $40 \mathrm{~min}$ ). Apart from PEF 3 and 7, there were significant differences $(p<0.05)$ between the various PEF conditions concerning the $\%$ reduction of the DPPH radical. M. oleifera leaves are known for their high content in total phenols, flavonols [38] and other flavonoids [56] and, therefore, the high \% reduction ability of the extracts was expected. 
Table 3. Antioxidant activity (\% inhibition of the $\mathrm{DPPH}^{\bullet}$ radical) of the extracts.

\begin{tabular}{cc}
\hline Sample Name & \% Inhibition of DPPH ${ }^{\bullet}$ Radical \\
\hline PEF 1 & $54.92(0.33)^{\mathrm{a} *}$ \\
PEF 2 & $60.83(0.24)^{\mathrm{b}}$ \\
PEF 3 & $74.77(0.50)^{\mathrm{c}}$ \\
PEF 4 & $85.32(0.61)^{\mathrm{d}}$ \\
PEF 5 & $98.31(0.67)^{\mathrm{e}}$ \\
PEF 6 & $77.03(0.32)^{\mathrm{f}}$ \\
PEF 7 & $73.91(0.49)^{\mathrm{c}}$ \\
PEF 8 & $70.19(0.29)^{\mathrm{g}}$ \\
Microwave (350 W) & $82.61(0.51)^{\mathrm{h}}$ \\
Ultrasound & $64.82(0.28)^{\mathrm{i}}$ \\
Boiling water & $70.72(0.37)^{\mathrm{g}}$ \\
Control & $42.94(0.12)^{\mathrm{k}}$ \\
\hline
\end{tabular}

* The results are presented as the means of three determinations. The standard deviation (SD) is given in parentheses. The different superscript letters denote statistically significant difference $(p<0.05)$.

The results of the ferric reducing antioxidant power (FRAP assay) are shown in Table 4. It appears that the reducing ability of the extracts on ferric ions followed the trend of the DPPH${ }^{\bullet}$ method. Again, the highest ferric reduction was achieved by the PEF 5 procedure $(108.22 \mu \mathrm{moL}$ AAE/g d.m.) followed by that of the PEF 4 procedure. The lowest reduction was achieved again by the control sample. The reduction of the ferric ions presented significant $(p<0.05)$ differences among the different PEF procedures (except for PEF 3 and 7). M. oleifera extracts have previously shown [57,58] high ferric ion reduction ability.

Table 4. Antioxidant activity (ferric reducing antioxidant power-FRAP assay) of the extracts.

\begin{tabular}{cc}
\hline Sample Name & Ferric Reducing Antioxidant Power $(\mu$ moL AAE/g Dry Matter) \\
\hline PEF 1 & $60.50(0.27)^{\mathrm{a} *}$ \\
PEF 2 & $66.16(0.39)^{\mathrm{b}}$ \\
PEF 3 & $81.40(0.27)^{\mathrm{c}}$ \\
PEF 4 & $94.08(0.59)^{\mathrm{d}}$ \\
PEF 5 & $108.22(0.77)^{\mathrm{e}}$ \\
PEF 6 & $86.08(0.29)^{\mathrm{f}}$ \\
PEF 7 & $81.48(0.31)^{\mathrm{c}}$ \\
PEF 8 & $77.70(0.24)^{\mathrm{g}}$ \\
Microwave (350 W) & $90.04(0.51)^{\mathrm{h}}$ \\
Ultrasound & $71.68(0.35)^{\mathrm{i}}$ \\
Boiling water & $78.12(0.30)^{\mathrm{g}}$ \\
Control & $47.78(0.14)^{\mathrm{k}}$
\end{tabular}

* The results are presented as the means of three determinations. The standard deviation (SD) is given in parentheses. The different superscript letters denote statistically significant difference $(p<0.05)$.

The results of the Rancimat method are shown in Table 5. Again, it appears that the results followed the same trend as those of the DPPH ${ }^{\bullet}$ and FRAP methods. The highest PF was achieved by the PEF 5 procedure $(\mathrm{PF}=3.7)$ followed by that of the $\mathrm{PEF} 4$ procedure $(\mathrm{PF}=3.0)$ and microwave-assisted extraction $(\mathrm{PF}=2.9)$, while the lowest was shown by the control $(\mathrm{PF}=1.0)$. No significant $(p<0.05)$ differences were presented among the PEF 3, 6, 7 and 8 procedures and boiling water extraction. M. oleifera leaf extracts (hot water extract) have previously shown [38] high antioxidant action ( $\mathrm{PF}=4.2$ ). This result was higher than that produced during the present work. This can be attributed to the different agroclimatic conditions and cultivation techniques. 
Table 5. Antioxidant activity (Protection Factor-Rancimat method) of the extracts.

\begin{tabular}{cc}
\hline Sample Name & Protection Factor \\
\hline PEF 1 & $1.5(0.1)^{\mathrm{a} *}$ \\
PEF 2 & $1.8(0.2)^{\mathrm{a}}$ \\
PEF 3 & $2.5(0.2)^{\mathrm{b}}$ \\
PEF 4 & $3.0(0.2)^{\mathrm{c}}$ \\
PEF 5 & $3.7(0.3)^{\mathrm{d}}$ \\
PEF 6 & $2.7(0.1)^{\mathrm{b}}$ \\
PEF 7 & $2.5(0.1)^{\mathrm{b}}$ \\
PEF 8 & $2.3(0.1)^{\mathrm{b}}$ \\
Microwave (350 W) & $2.9(0.2)^{\mathrm{c}}$ \\
Ultrasound & $2.0(0.1)^{\mathrm{a}}$ \\
Boiling water & $2.3(0.1)^{\mathrm{b}}$ \\
Control & $1.0(0.1)^{\mathrm{d}}$
\end{tabular}

* The results are presented as the means of three determinations. The standard deviation (SD) is given in parentheses. The different superscript letters denote statistically significant difference $(p<0.05)$.

\section{Conclusions}

The scope of this work was to determine the possibility of application of the PEF technique (with various parameters) to the production of plant extracts. During this study, the PEF procedure was used for the production of extracts from the freeze-dried leaves of M. oleifera. Other, well-known extraction techniques, namely, microwave- and ultrasound-assisted extractions, the simple boiling water extraction procedure and simple maceration with water (as the control), were used for comparison purposes. The efficiency of the extraction was determined by means of total phenol concentration assays. Additionally, the antioxidant activity of the extracts was determined using three methods, namely, the DPPH ${ }^{\bullet}$, FRAP and Rancimat methods. The highest extraction of total phenols was achieved by the PEF procedure, using a PD of $20 \mathrm{msec}$ and a PI of $100 \mu \mathrm{sec}$ for a $40 \mathrm{~min}$ treatment. All methods used for the determination of the antioxidant action showed that the activity of the extracts was proportional to the total phenol content. Concerning the PEF procedure, a low PD with a high PI is proposed in order to achieve higher extraction efficiency.

According to the results of the present study, PEF technology is a promising alternative compared to other methods (i.e., boiling, microwave-assisted and ultrasound-assisted extractions, etc.) for the extraction of important compounds from plant material. Furthermore, PEF is less power demanding (and hence less expensive) and, more importantly, does not increase the temperature $\left(<{ }^{\circ} \mathrm{C}\right)$ of the sample (or extraction medium), which means that the production of high-value extracts is possible, especially in the case of sensitive compounds. Future research should be focused on the optimization of the process by using different PEF parameters (pulse duration, pulse interval and electric field strength) or by using other electrical pulse shapes in order to increase the extraction efficiency.

Author Contributions: Conceptualization, V.G.D. and S.I.L.; Funding acquisition, S.I.L.; Methodology, E.B.; Analysis, E.B. and I.G.; Statistical analysis, G.B.; Supervision, S.I.L.; Writing-original draft, E.B.; Writing-review and editing, E.B., V.G.D. and S.I.L.

Funding: This research has been co-financed by the European Union and Greek national funds through the Operational Program Competitiveness, Entrepreneurship and Innovation, under the call RESEARCH-CREATE-INNOVATE (project code: T1EDK-03762).

Conflicts of Interest: The authors declare no conflict of interest.

\section{References}

1. Luque de Castro, M.D.; Garcia-Ayuso, L.E. Soxhlet extraction of solid materials: An outdated technique with a promising innovative future. Anal. Chim. Acta 1998, 369, 1-10. [CrossRef] 
2. Azmir, J.; Zaidul, I.S.M.; Rahman, M.M.; Sharif, K.M.; Mohamed, A.; Sahena, F.; Jahurul, M.H.A.; Ghafoor, K.; Norulaini, N.A.N.; Omar, A.K.M. Techniques for extraction of bioactive compounds from plant materials: A review. J. Food Eng. 2013, 117, 426-436. [CrossRef]

3. Ho, S.; Mittal, G.S. High voltage pulsed electrical field for liquid food pasteurization. Food Rev. Int. 2000, 16, 395-434. [CrossRef]

4. Wouters, P.C.; Alvarez, I.; Angersbach, A.; Knorr, D. Critical factors determining inactivation kinetics by pulsed electric field food processing. Trends Food Sci. Technol. 2001, 12, 112-121. [CrossRef]

5. Vorobiev, E.; Lebovka, N.I. Electrotechnologies for Extraction from Food Plants and Biomaterials, 1st ed.; Springer: New York, NY, USA, 2008; pp. 39-82.

6. Barba, J.F.; Parniakov, O.; Pereira, A.S.; Wiktor, A.; Grimi, N.; Boussetta, N.; Saraiva, G.; Raso, J.; Martin-Belloso, O.; et al. Current applications and new opportunities for the use of pulsed electric fields in food science and industry. Food Res. Int. 2015, 77, 773-798. [CrossRef]

7. Puertolas, E.; Luengo, E.; Alvarez, I.; Raso, J. Improving mass transfer to soften tissues by pulsed electric fields: Fundamentals and applications. Annu. Rev. Food Sci. Technol. 2012, 3, 263-282. [CrossRef] [PubMed]

8. El-Belghiti, K.; Vorobiev, E. Modelling of solute aqueous extraction from carrots subjected to a pulsed electric field pre-treatment. Biosyst. Eng. 2005, 90, 289-294. [CrossRef]

9. Lebovka, N.I.; Shynkaryk, M.V.; El-Belghiti, K.; Benjelloun, H.; Vorobiev, E. Plasmolysis of sugarbeet: Pulsed electric fields and thermal treatment. J. Food Eng. 2007, 80, 639-644. [CrossRef]

10. Loginova, K.; Shynkaryk, M.V.; Lebovka, N.I.; Vorobiev, E. Acceleration of soluble matter extraction from chicory with pulsed electric fields. J. Food Eng. 2010, 96, 374-379. [CrossRef]

11. Gachovska, T.K.; Cassada, D.; Subbiah, J.; Hanna, M.; Thippareddi, H.; Snow, D. Enhanced anthocyanin extraction from red cabbage using pulsed electric field processing. J. Food Sci. 2010, 75, E323-E329. [CrossRef]

12. Abdullah, S.H.; Zhao, S.; Mittal, G.S.; Baik, O.-D. Extraction of podophyllotoxin from Podophyllum peltatum using pulsed electric field treatment. Sep. Purif. Technol. 2012, 93, 92-97. [CrossRef]

13. Zderic, A.; Zondervan, E.; Meuldijk, J. Breakage of cellular tissue by pulsed electric field: Extraction of polyphenols from fresh tea leaves. Chem. Eng. Trans. 2013, 32, 1795-1800.

14. He, G.; Yin, Y.; Yan, L.; Yu, Q. Fast extraction of chitosan from shrimp shell by high intensity pulsed electric fields. Nongye Gongcheng Xuebao/Trans. Chin. Soc. Agric. Eng. 2011, 27, 344-348.

15. Zhou, Y.; Sui, S.; Huang, H.; He, G.; Wang, S.; Yin, Y.; Ma, Z. Process optimization for extraction of fishbone calcium assisted by high intensity pulsed electric fields. Nongye Gongcheng Xuebao/ Trans. Chin. Soc. Agric. Eng. 2012, 28, 265-270.

16. Pourzaki, A.; Mirzaee, H.; Hemmati Kakhki, A. Using pulsed electric field for improvement of components extraction of saffron (Crocus sativus) stigma and its pomace. J. Food Process. Preserv. 2013, 37, 1008-1013. [CrossRef]

17. Ade-Omowaye, B.I.O.; Angersbach, A.; Taiwo, K.A.; Knorr, D. The use of pulsed electric fields in producing juice from paprika (Capsicum annuum L.). J. Food Process. Preserv. 2001, 25, 353-365. [CrossRef]

18. Drosou, F.; Yang, E.; Marinea, M.; Dourtoglou, E.G.; Chatzilazarou, A.; Dourtoglou, V.G. An assessment of potential applications with pulsed electric field in wines. In Proceeding of the 40th World Congress of Vine and Wine, Sofia, Bulgaria, 29 May-2 June 2017. [CrossRef]

19. Tiwary, K.B. Ultrasound: A clean, green extraction technology. Trends Anal. Chem. 2015, 71, 100-109. [CrossRef]

20. Mason, T.J.; Paniwnyk, L.; Lorimer, J.P. The uses of ultrasound in food technology. Ultrason. Sonochem. 1996, 3, 253-260. [CrossRef]

21. Chemat, F.; Tomao, V.; Virot, M. Ultrasound-Assisted Extraction in Food Analysis. In Handbook of Food Analysis Instruments; Otles, S., Ed.; CRC Press: New York, NY, USA, 2008; pp. 85-94.

22. Rostagno, M.A.; Palma, M.; Barroso, C.G. Ultrasound-assisted extraction of soy isoflavones. J. Chromatogr. A 2003, 1012, 119-128. [CrossRef]

23. Herrera, M.C.; Luque de Castro, M.D. Ultrasound-assisted extraction for the analysis of phenolic compounds in strawberries. Anal. Bioanal. Chem. 2004, 379, 1106-1112. [CrossRef]

24. Li, H.; Chen, B.; Yao, S. Application of ultrasonic technique for extracting chlorogenic acid from Eucommia ulmodies Oliv. (E. ulmodies). Ultrason. Sonochem. 2005, 12, 295-300. [CrossRef]

25. Yang, Y.; Zhang, F. Ultrasound-assisted extraction of rutin and quercetin from Euonymus alatus (Thunb.) Sieb. Ultrason. Sonochem. 2008, 15, 308-313. [CrossRef] [PubMed] 
26. Yang, L.; Wang, H.; Zu, Y-G.; Zhao, C.; Zhang, L.; Chen, X.; Zhang, Z. Ultrasound-assisted extraction of the three terpenoid indole alkaloids vindoline, catharanthine and vinblastine from Catharanthus roseus using ionic liquid aqueous solutions. Chem. Eng. J. 2011, 172, 705-712. [CrossRef]

27. Ghafoor, K.; Hui, T.; Choi, Y.H. Optimization of ultrasound-assisted extraction of total anthocyanins from grape peel. J. Food Biochem. 2011, 35, 735-746. [CrossRef]

28. Zu, G.; Zhang, R.; Yang, L.; Ma, C.; Zu, Y.; Wang, W.; Zhao, C. Ultrasound assisted extraction of carnosic acid and rosmarinic acid using ionic liquid solution from Rosmarinus officinalis. Int. J. Mol. Sci. 2012, 13, 11027-11043. [CrossRef] [PubMed]

29. Pare, J.J.R.; Belanger, J.M.R.; Stafford, S.S. Microwave-assisted process (MAP ${ }^{\mathrm{TM}}$ ): A new tool for the analytical laboratory. Trends Anal. Chem. 1994, 13, 176-184. [CrossRef]

30. Chemat, F.; Fabiano-Tixier, A.S.; Abert Vian, M.; Allaf, T.; Vorobiev, E. Solvent-free extraction of food and natural products. Trends Anal. Chem. 2015, 71, 157-168. [CrossRef]

31. Chung-Hun, C.; Yusoff, R.; Gek-Cheng, N.; Kung, W.L.F. Microwave-assisted extractions of active ingredients from plants. J. Chromatogr. A 2011, 1218, 6213-6225.

32. Pan, X.; Niu, G.; Liu, H. Microwave-assisted extraction of tea polyphenols and tea caffeine from green tea leaves. Chem. Eng. Process. 2003, 42, 129-133. [CrossRef]

33. Shu, Y.Y.; Ko, M.Y.; Chang, Y.S. Microwave-assisted extraction of ginsenosides from ginseng root. Microchem. J. 2003, 74, 131-139. [CrossRef]

34. Dhobi, M.; Mandal, V.; Hemalatha, S. Optimization of microwave assisted extraction of bioactive flavolignan-silybinin. J. Chem. Metrol. 2009, 3, 13-23.

35. Asghari, J.; Ondruschka, B.; Mazaheritehrani, M. Extraction of bioactive chemical compounds from the medicinal Asian plants by microwave irradiation. J. Med. Plants Res. 2011, 5, 495-506.

36. Chiremba, C.; Rooney, L.W.; Trust, B.J. Microwave-assisted extraction of bound phenolic acids in bran and flour fractions from sorghum and maize cultivars varying in hardness. J. Chromatogr. A 2012, 1012, 119-128. [CrossRef] [PubMed]

37. Hui, T.; Ghafoor, K.; Choi, Y.H. Optimization of microwave-assisted extraction of active components from Chinese quince using response surface methodology. J. Korean Soc. Appl. Biol. Chem. 2009, 52, 694-701.

38. Lalas, S.; Athanasiadis, V.; Karageorgou, I.; Batra, G.; Nanos, D.G.; Makris, P.D. Nutritional characterization of leaves and herbal tea of Moringa oleifera cultivated in Greece. J. Herbs Spices Med. Plants 2017, 23, 320-333. [CrossRef]

39. Padayachee, B.; Baijnath, H. An overview of the medicinal importance of Moringaceae. J. Med. Plants Res. 2012, 6, 5831-5839.

40. Saini, R.K.; Sivanesan, I.; Keum, Y.S. Phytochemicals of Moringa oleifera: A review of their nutritional, therapeutic and industrial significance. 3 Biotech 2016, 6, 203. [CrossRef]

41. Karakashov, B.; Grigorakis, S.; Loupassaki, S.; Makris, D.P. Optimisation of polyphenol extraction from Hypericum perforatum (St. John's Wort) using aqueous glycerol and response surface methodology. J. Appl. Res. Med. Aromat. Plants 2015, 2, 1-8. [CrossRef]

42. Karvela, E.; Makris, D.P.; Karathanos, V.T. Implementation of response surface methodology to assess the antiradical behaviour in mixtures of ascorbic acid and $\alpha$-tocopherol with grape (Vitis vinifera) stem extracts. Food Chem. 2012, 132, 351-359. [CrossRef]

43. Fuster, M.D.; Lampi, A.M.; Hopia, A.; Kamal-Eldin, A. Effects of $\alpha$ - and $\gamma$ - tocopherols on the autoxidation of purified sunflower triacylglycerols. Lipids 1998, 33, 715-722. [CrossRef]

44. Lalas, S.; Dourtoglou, V. Use of rosemary extract in preventing oxidation during deep fat frying of potato chips. J. Am. Oil Chem. Soc. 2003, 80, 579-583. [CrossRef]

45. Brodelius, P.E.; Funk, C.; Shillito, R.D. Permeabilization of cultivated plant cells by electroporation for release of intracellularly stored secondary products. Plant Cell Rep. 1988, 7, 186-188. [CrossRef] [PubMed]

46. Delsart, C. Champs Electriques Pulses et Decharges Electriques de Haute Tension Pour 1' Extraction et la Stabilisation en Oenologie. Ph.D. Thesis, Doctorat de l' Université Bordeaux 2, Centre de Recherche de Bordeaux Aquitaine, Villenave D'Ornon, France, 13 December 2012.

47. Doenenburg, H.; Knorr, D. Cellular permeabilisation of cultured plant tissue by high electric field pulses or ultra high pressure for the recovery of secondary metabolites. Food Biotechnol. 1993, 7, 35-48. [CrossRef]

48. Fincan, M.; De Vito, F.; Dejmek, P. Pulsed electric field treatment for solid-liquid extraction of red beetroot pigment. J. Food Eng. 2004, 64, 381-388. [CrossRef] 
49. Tedjo, W.; Eshtiaghi, M.N.; Knorr, D. Einsatz, nicht thermischer verfahren zur zell-permeabilisierung von weintrauben und gewinnung von inhaltsstoffen. Flüssiges Obst. 2002, 9, 578-583.

50. Boussetta, N.; Vorobiev, E.; Le, L.H.; Cordin-Falcimaigne, A.; Lanoisellé, J.-L. Application of electrical treatments in alcoholic solvent for polyphenols extraction from grape seeds. LWT Food Sci. Technol. 2012, 46, 127-134. [CrossRef]

51. Eshtiaghi, M.N.; Knorr, D. High electric field pulse pretreatment: Potential for sugar beet processing. J. Food Eng. 2002, 53, 265-272. [CrossRef]

52. Ade-Omowaye, B.I.O.; Angersbach, A.; Taiwo, K.A.; Knorr, D. Use of pulsed electric field pretreatment to improve dehydration characteristics of plant based foods. Trends Food Sci. Technol. 2001, 12, 285-295. [CrossRef]

53. Koehler, E.; Toepfl, S.; Knorr, D.; Pulz, O. Unconventional procedures for the production and stabilization of extracts with active agents. In Proceedings of the 6th European Workshop of European Society of Microalgal Biotechnology, Potsdam, Germany, 23 May 2005.

54. Kedare, S.B.; Singh, R.P. Genesis and development of DPPH method of antioxidant assay. J. Food Sci. Technol. 2011, 48, 412-422. [CrossRef]

55. Pisoschi, A.M.; Negulescu, G.P. Methods for total antioxidant activity determination: A review. Biochem. Anal. Biochem. 2011, 1, 106. [CrossRef]

56. Lalas, S.; Tsaknis, J. Extraction and identification of natural antioxidant from the seeds of Moringa oleifera tree variety of Malawi. J. Am. Oil Chem. Soc. 2002, 79, 677-683. [CrossRef]

57. Tekle, E.W.; Sahu, N.P.; Makesh, M. Antioxidative and antimicrobial activities of different solvent extracts of Moringa oleifera: An in vitro evaluation. Int. J. Sci. Res. 2015, 5, 1-4.

58. Luqman, S.; Srivastava, S.; Kumar, R.; Kumar Maurya, A.; Chanda, D. Experimental assessment of Moringa oleifera leaf and fruit for its antistress, antioxidant, and scavenging potential using in vitro and in vivo assays. Evid. Based Complement. Altern. Med. 2012, 2012, 519084. [CrossRef] [PubMed]

(C) 2019 by the authors. Licensee MDPI, Basel, Switzerland. This article is an open access article distributed under the terms and conditions of the Creative Commons Attribution (CC BY) license (http:/ / creativecommons.org/licenses/by/4.0/). 